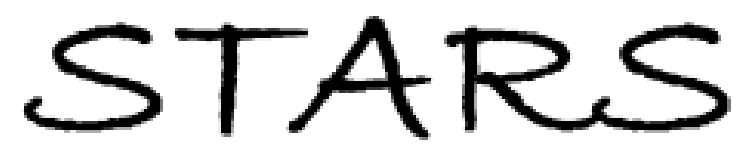

University of Central Florida

STARS

Faculty Bibliography 2000s

Faculty Bibliography

$1-1-2003$

\title{
Hexagonal lattice of 10-nm magnetic dots
}

\author{
L. Malkinski \\ R. E. Camley \\ Z. Celinski
}

T. A. Winningham

University of Central Florida

S. G. Whipple

See next page for additional authors

Find similar works at: https://stars.library.ucf.edu/facultybib2000 University of Central Florida Libraries http://library.ucf.edu

This Article; Proceedings Paper is brought to you for free and open access by the Faculty Bibliography at STARS. It has been accepted for inclusion in Faculty Bibliography 2000s by an authorized administrator of STARS. For more information, please contact STARS@ucf.edu.

\section{Recommended Citation}

Malkinski, L.; Camley, R. E.; Celinski, Z.; Winningham, T. A.; Whipple, S. G.; and Douglas, K., "Hexagonal lattice of 10-nm magnetic dots" (2003). Faculty Bibliography 2000s. 3910.

https://stars.library.ucf.edu/facultybib2000/3910

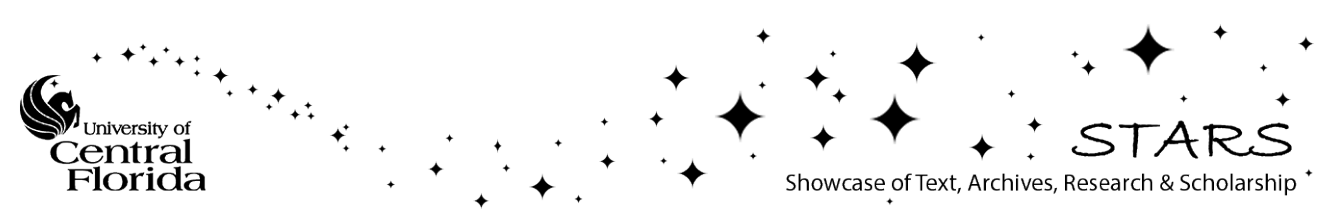




\section{Authors}

L. Malkinski, R. E. Camley, Z. Celinski, T. A. Winningham, S. G. Whipple, and K. Douglas 


\section{Hexagonal lattice of 10-nm magnetic dots}

Cite as: Journal of Applied Physics 93, 7325 (2003); https://doi.org/10.1063/1.1543861

Published Online: 09 May 2003

L. Malkinski, R. E. Camley, Z. Celinski, T. A. Winningham, S. G. Whipple, and K. Douglas

\section{HDDEN}
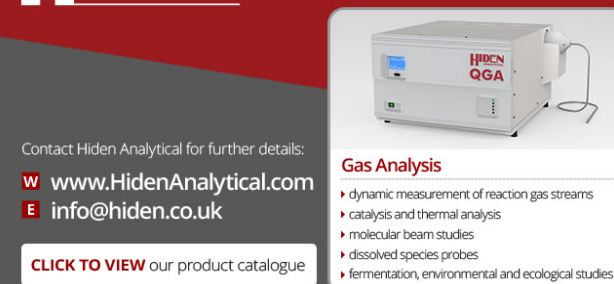

Gas Analysis

- dynamic measurement of reaction gas streams - cataysis and thermal analysis

- molecular beam studes

, dissohed species probes

\section{Instruments for Advanced Science}
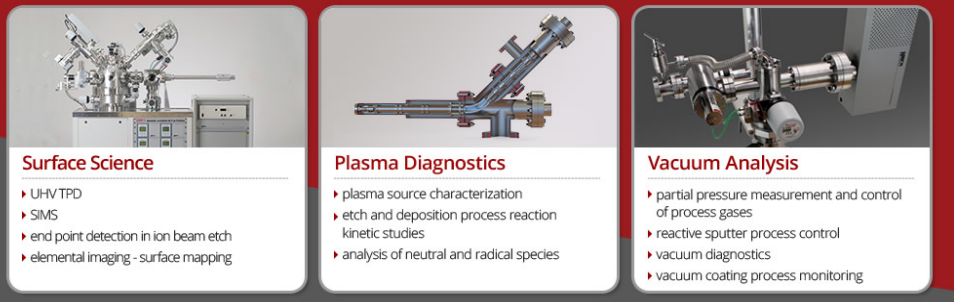

Journal of Applied Physics 93, 7325 (2003); https://doi.org/10.1063/1.1543861

93, 7325

(c) 2003 American Institute of Physics. 


\title{
Hexagonal lattice of $10-\mathrm{nm}$ magnetic dots
}

\author{
L. Malkinski ${ }^{\mathrm{a})}$ \\ University of New Orleans, AMRI, New Orleans, Louisiana 70148 \\ R. E. Camley and Z. Celinski \\ Department of Physics, University of Colorado at Colorado Springs, Colorado 80919
}

T. A. Winningham

Department of Physics, University of Central Florida, Orlando, Florida 32816

S. G. Whipple and K. Douglas

Department of Physics, University of Colorado, Boulder, Colorado 80309

(Presented on 13 November 2002)

\begin{abstract}
We have grown precisely ordered and precisely located arrays of ultra-small magnetic dots. The nanofabrication process is based on the use of a protein crystal etch mask which is used to create a hexagonal lattice of holes in Si substrates. An assembly of $(\mathrm{Fe} / \mathrm{Pd})_{4}$ dots with the average dot size of $10 \mathrm{~nm}$ in diameter, $6.5 \mathrm{~nm}$ height, and an average separation between dot centers of $22 \mathrm{~nm}$ was grown using molecular-beam epitaxy. The dot locations are determined by the biological mask that is used to create ordered arrays of $\sim 4 \mathrm{~nm}$ deep holes in Si. Fe/Pd multilayers $(1 \mathrm{~nm}$ thick Fe and $0.4 \mathrm{~nm}$ thick Pd layers) were deposited to create dots within these holes. The dots extend $\sim 2.5 \mathrm{~nm}$ above the surface, with a thicker $(1.5 \mathrm{~nm})$ final layer of Pd for protection of these structures during measurements. Magneto-optical Kerr effect and magnetometry data showed that these objects are magnetic even at room temperature and are fairly soft with a coercive field of $\sim 40$ Oe. Measurements of the hysteresis loop revealed that magnetization is in plane and that $4 \pi \mathrm{M}_{\text {eff }}$ is on the order of 15 kG. () 2003 American Institute of Physics. [DOI: 10.1063/1.1543861]
\end{abstract}

\section{INTRODUCTION}

During the last two decades, the use of ultrahigh vacuum technology has made possible the creation of ultrathin magnetic structures with interfaces that are sharp on the atomic scale. This development has brought not only other ways of engineering artificial magnetic materials but also exciting discoveries such as exchange coupling, giant magnetoresistance, and magnetic tunneling. ${ }^{1}$ As a result, the significant interest by industry in different magnetic materials and devices has rejuvenated activities in the field of ultrathin magnetic structures.

One issue of paramount importance is the patterning of ultrathin magnetic structures into objects of nanometer scale ${ }^{2}$ and the study of their static and dynamic properties. There are techniques, such as electron-beam or x-ray lithography, which make such patterning possible, although there are significant restrictions. For example, electron-beam lithography can make objects on a scale of $10 \mathrm{~nm}$, but its time-intensive serial nature makes large-area patterning with this technique unfeasible. X-ray photolithography requires use of synchrotron radiation, which is not commonly accessible. The aim of our work was to grow patterned magnetic structures using a biologically derived parallel fabrication technique and to study the magnetic properties of the structures. This approach allowed us to create large areas of patterned magnetic structures $\left(\sim \mathrm{cm}^{2}\right)$. In this article, we describe in detail the preparation of Si wafers, the growth process, and the results

\footnotetext{
${ }^{\text {a)} E l e c t r o n i c ~ m a i l: ~ 1 m a l k i n s @ b r a i n . u c c s . e d u ~}$
}

of superconducting quantum interference device magnetometer (SQUID) and magneto-optical Kerr effect (MOKE) measurements on a regular hexagonal array of $10 \mathrm{~nm}$ in diameter $(\mathrm{Fe} / \mathrm{Pd})_{4}$ magnetic dots.

\section{SAMPLE PREPARATION}

The growth process is based on the use of twodimensional protein crystals as an etch mask. The preparation of the protein crystals and their use as masks have been described in previous publications. ${ }^{3-6}$ They are native twodimensional crystals that form the surface layer ( $S$ layer) of the archaebacteria sulfolobus acidocaldarius. They possess a hexagonal array of pores with a $22 \mathrm{~nm}$ lattice constant and pore diameters of $10 \mathrm{~nm}$. The size of the native protein crystal fragments is on the order of 1 to $2 \mu \mathrm{m}$ in diameter.

The protein crystals were applied to the $\mathrm{Si}$ wafer in an aqueous suspension. The density of the surface coverage is controlled by regulating the protein concentration in the aqueous suspension. The $\mathrm{Si}$ substrates used in our studies were approximately $50 \%$ covered with $S$ layers, which insured that we avoided overlapping protein crystal fragments. After a short drying process, the $\mathrm{Si}$ wafers were placed in an electron-beam deposition system where a layer of $\mathrm{Cr}$ was deposited under an angle of approximately $60^{\circ}$. The periodic topography of the protein crystals produced a shadow at each pore site, effectively creating an ordered array of holes in the deposited $\mathrm{Cr}$ film. Inductively coupled plasma was used to transfer the pattern of the protein crystals into the Si substrate in the form of an ordered array of holes, verified by atomic force microscopy (AFM). Areas not covered by $\mathrm{Cr}$ 


\begin{tabular}{|c|}
\hline $1.5 \mathrm{~nm} \mathrm{Pd}$ \\
\hline $1 \mathrm{~nm} \mathrm{Fe}$ \\
\hline $0.4 \mathrm{~nm} \mathrm{Pd}$ \\
\hline $1 \mathrm{~nm} \mathrm{Fe}$ \\
\hline $0.4 \mathrm{~nm} \mathrm{Pd}$ \\
\hline $1 \mathrm{~nm} \mathrm{Fe}$ \\
\hline $0.4 \mathrm{~nm} \mathrm{Pd}$ \\
\hline $1 \mathrm{~nm} \mathrm{Fe}$ \\
\hline
\end{tabular}

FIG. 1. A schematic diagram of the individual magnetic dot.

are etched while those with $\mathrm{Cr}$ are protected. The size of the holes was adjusted by varying the etch parameters and time. These $\mathrm{Si}$ substrates, with the $\mathrm{Cr} /$ protein crystal mask still in place, were introduced into the ultrahigh vacuum deposition system.

We grew the arrays of magnetic dots at room temperature in a molecular-beam epitaxy system. ${ }^{7}$ Using Knudsen cells, we deposited four $1 \mathrm{~nm}$ thick Fe layers separated by $0.4 \mathrm{~nm}$ thick Pd layers. The final Pd layer was $1.5 \mathrm{~nm}$ thick to prevent oxidization during measurements in ambient condition. Figure 1 shows a schematic diagram of our individual magnetic dot. The thicknesses of the individual layers and the rate of growth $(\sim 0.1 \mathrm{~nm} / \mathrm{min})$ were monitored by a thickness monitor. In addition to the patterned $\mathrm{Si}$ substrate, we deposited a control sample directly on bare unpatterned $\mathrm{Si}$. Despite the fact that the Si substrates were introduced to the molecular-beam epitaxy system with the protein mask on them, we did not observe an increase of the base pressure, indicating that outgassing was minimal. After deposition, we removed the protein mask leaving arrays of $(\mathrm{Fe} / \mathrm{Pd})_{4}$ dots on the Si substrates.

AFM measurements were made in air using a Digital Instruments Nanoscope III operating in tapping mode (Fig. 2). Dot diameters were on the order of $10 \mathrm{~nm}$. Because we have not yet optimized our mask removal technique, defects and missing dots can be found in the array, most likely created during the removal or liftoff process. Magnetic force microscopy measurements were attempted, but preliminary efforts have been unsuccessful. We have had difficulty getting the resolution below $30 \mathrm{~nm}$, and thus have not been able to image individual dots with magnetic contrast.

\section{MAGNETIC MEASUREMENTS}

Before presenting the magnetic results we would like to comment on the question of superparamagnetic behavior in these structures. The prepared magnetic dots are very small $(10 \mathrm{~nm}$ in diameter and $6.5 \mathrm{~nm}$ in height). Pure iron objects with such small dimensions are superparamagnetic above approximately $50 \mathrm{~K}$ since thermal fluctuations are much larger than the anisotropy energy. To increase the blocking temperature one needs to introduce an additional anisotropy to

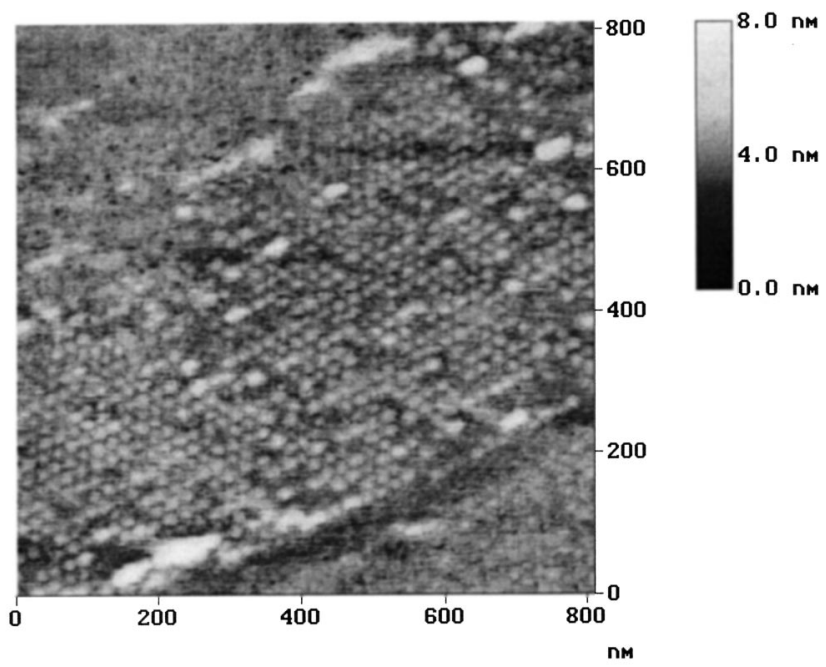

FIG. 2. Atomic force microscopy image of $(\mathrm{Fe} / \mathrm{Pd})_{4}$ magnetic dots grown on a Si substrate. The thickness of an individual Fe layer within a dot was 1 $\mathrm{nm}$, the thickness of Pd between Fe layers was $0.4 \mathrm{~nm}$, and the dots were capped with a $1.5 \mathrm{~nm}$ thick Pd layer.

the structures. By layering the Fe with $\mathrm{Pd}$, nine $\mathrm{Pd} / \mathrm{Fe}$ interfaces were created which significantly increased the effective anisotropy. ${ }^{8}$ Furthermore, the $0.4 \mathrm{~nm}$ thick Pd interlayer between the Fe layers produces a strong ferromagnetic coupling between the Fe films, and each dot thus responds as a single magnetic unit. ${ }^{9}$

We conducted a series of magnetic measurements using a MOKE system and a SQUID magnetometer. Both techniques revealed that the system is ferromagnetic even at room temperature because a coercive field was observed. The shape of the hysteresis loops was very different for the patterned samples than that observed for samples with a continuous film (see Fig. 3). For the continuous film structures we observed a square hysteresis loop with a coercive field of 10 Oe; the patterned structures exhibited $S$-shape hysteresis loops with larger coercive fields (on the order of $35 \mathrm{Oe}$ ).

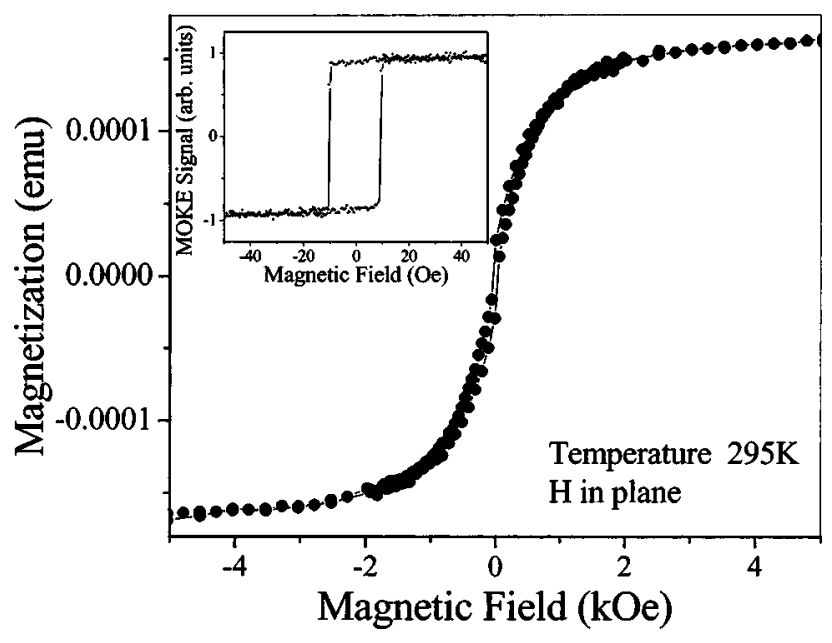

FIG. 3. Hysteresis loop for the magnetic dot array measured at $295 \mathrm{~K}$ with the magnetic field applied in the plane of the structure. Inset shows data for identical continuous film structure. Note the squareness of the hysteresis loop for the continuous film structure. 


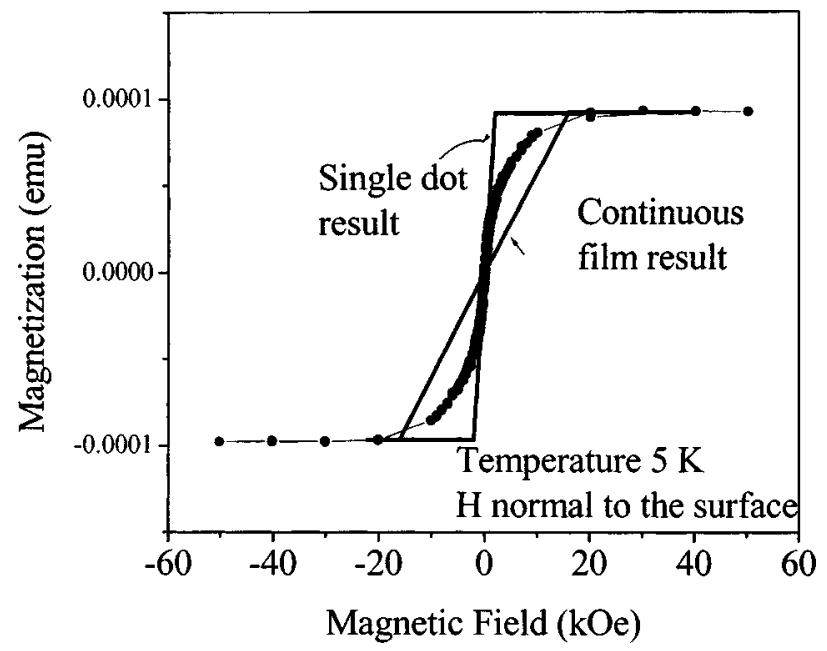

FIG. 4. Hysteresis loop measured at $5 \mathrm{~K}$ with the magnetic field applied normal to the sample plane. The solid lines represent theoretical calculations of the magnetization vs field for the continuous film structure and for an array of independent dots with the appropriate demagnetizing factors.

Moreover, the patterned structure requires a field of $4 \mathrm{kOe}$ to reach saturation. The saturation field decreases with decreasing temperature to $3 \mathrm{kOe}$ at $5 \mathrm{~K}$. The coercivity increased with decreasing temperature, reaching a value of 90 Oe at 5 K. Since the samples do not exhibit translational invariance over the range larger than $2 \mu \mathrm{m}$, the measured response is an average for all dots in different patterned regions.

The out-of-plane measurements showed that it was necessary to apply a magnetic field larger than $15 \mathrm{kOe}$ in order to saturate the sample (see Fig. 4). This indicates that the magnetization is in the plane of the sample. Moreover, the shape the hysteresis loop in this configuration is very different than that found in continuous films and also different for that expected for an array of independent dots. In Fig. 4 the solid lines represent theoretical calculations of the magnetization versus field for the continuous film structure and for an array of independent dots with demagnetizing factors $N_{x}$ $=N_{y}=0.24$ and $N_{z}=0.52$ (where $z$ is the axis of the cylinder). ${ }^{10}$ The calculation for $M(H)$ for the independent dot is based on a minimization of the magnetostatic energy and Zeeman energy and assuming that the interior fields can be appropriately approximated by the demagnetizing factors. The fact that the measurements lie in between these two limits suggests that there is substantial interaction between the dots.

Figure 5 presents data on the temperature dependence of the coercivity for applied field both perpendicular and in plane. The coercivity decreases slowly as temperature increases for both configurations. This suggests that the superparamagnetic limit is well above room temperature. It is interesting to note that the coercivity is larger for the out-ofplane geometry.

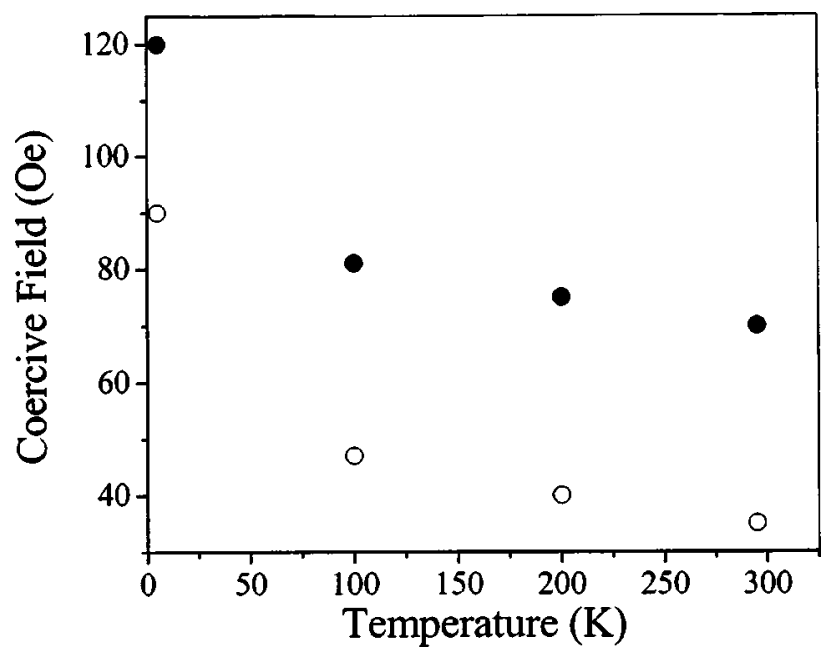

FIG. 5. The coercive field as a function of the temperature measured with the magnetic field applied in plane (open symbols) and normal (solid symbols) to the structure.

In conclusion, we have grown series of ultra small $(\mathrm{Fe} / \mathrm{Pd})_{4}$ dot arrays. The magnetic properties of the dot arrays are very different from those of the equivalent continuous films. The coercive field for the dot array is increased by a factor of three and the saturation field is increased by a factor of over 100. The out-of-plane results showed that the behavior of our system lies between that of a continuous film and an array of independent dots, indicating that the interaction between these dots is important. The presence of coercivity and the shape of the hysteresis loops indicate that these dots are magnetic even at room temperature.

Work at UCCS was supported by the National Science Foundation (DMR-9970789 and DMR-0114189) and Army Research Office (DAAG19-00-1-0146 and DAAD19-02-10174) while research at UC-Boulder was supported by the AFOSR (Grant No. F49620-99-1-0105).

${ }^{1}$ B. Heinrich and J. F. Cochran, Adv. Phys. 42, 523 (1993).

${ }^{2}$ See, for example, J. I. Martín, J. Nogués, Kai Liu, J. L. Vicent, and Ivan K. Schuller, J. Magn. Magn. Mater., 256, 449 (2003) and the references therein.

${ }^{3}$ K. Douglas, N. Clark, and K. Rothschild, Appl. Phys. Lett. 48, 676 (1986).

${ }^{4}$ K. Douglas, G. Devaud, and N. Clark, Science 257, 642 (1992).

${ }^{5}$ T. A. Winningham, H. P. Gillis, D. A. Choutov, K. P. Martin, J. T. Moore, and K. Douglas, Surf. Sci. 406, 221 (1998).

${ }^{6}$ T. A. Winningham, S. G. Whipple, and K. Douglas, J. Vac. Sci. Technol. B 19(5), 1796 (2001).

${ }^{7}$ Z. Celinski, J. Vac. Sci. Technol. A 19, 383 (2001).

${ }^{8}$ B. Heinrich, Z. Celinski, J. F. Cochran, A. S. Arrott, and K. Myrtle, J. Appl. Phys. 70, 5769 (1991).

${ }^{9}$ Z. Celinski and B. Heinrich, J. Magn. Magn. Mater. 99, L25 (1991).

${ }^{10}$ Du Xing Chen, James A. Brug, and Ronald B. Goldfarb, IEEE Trans. Magn. 27, 3601 (1991). 